\title{
Scientometric Evaluation of Published Articles in Travel Medicine and Global Health
}

\author{
William Wen $\mathrm{Oh}^{1}$, Nizrull Nasir ${ }^{2}$, Gerard Thomas Flaherty ${ }^{1,3 *}$ \\ ${ }^{1}$ School of Medicine, National University of Ireland Galway, Galway, Ireland \\ ${ }^{2}$ School of Medicine and Medical Science, University College Dublin, Dublin, Ireland \\ ${ }^{3}$ School of Medicine, International Medical University, Kuala Lumpur, Malaysia
}

Corresponding Author: Gerard Thomas Flaherty, MD, Professor, School of Medicine, National University of Ireland Galway, Galway, Ireland. Tel: +353-91495469, Fax: +353-91494540, Email: gerard.flaherty@nuigalway.ie

Received March 24, 2021; Accepted April 17, 2021; Online Published April 23, 2021

\begin{abstract}
Introduction: Travel medicine has become firmly established as a medical discipline and, as such, it should undergo periodic assessment of its productivity. Scientometrics is a field of study related to data science, which concerns itself with the measurement and analysis of published scholarly literature.

Methods: A scientometric evaluation was conducted of all 240 articles published through February 2021 in the International Journal of Travel Medicine and Global Health (IJTMGH), one of the few academic journals dedicated to the study of travel medicine.

Results: The majority of articles belonged to the general category of travel medicine $(62 \%, n=149)$, with $38 \%$ of articles ( $n=91)$ being focused on global health and non-travel related infectious diseases. The 149 travel medicine-related articles mapped onto the Body of Knowledge syllabus of the International Society of Travel Medicine, with the majority of articles addressing the domain of pre-travel assessment of travellers $(49.7 \%, n=74)$, including the sub-domains of patient evaluation, special populations of travellers, special itineraries, prevention and self-treatment, and communication of risks to travellers. The most common thematic designation of IJTMGH articles related to medical and health tourism $(12.1 \%, n=29)$. High levels of geographic diversity, multi-authorship and inter-institutional collaboration were observed in the journal. The subject matter of the most cited and most popular articles reflected the broad coverage of travel medicine and global health by IJTMGH.

Conclusion: We recommend that future bibliometric and citation analyses be performed, which will further enhance our understanding of the evolution of these dynamic fields of academic study.

Keywords: Travel Medicine, Global Health, Citation Analysis, Bibliometric Analysis, Scientometrics
\end{abstract}

Citation: Oh WW, Nasir N, Flaherty GT. Scientometric Evaluation of Published Articles in Travel Medicine and Global Health. Int J Travel Med Glob Health. 2021;9(2):73-77. doi:10.34172/ijtmgh.2021.12.

\section{Introduction}

Despite having to adapt to the disruptive effects of the coronavirus disease 2019 (COVID-19) pandemic, published travel medicine research continues unabated and reflects the rapid evolution of this dynamic specialism. From its origins some four decades ago, travel medicine has firmly established itself as a medical discipline in most developed countries, while being formally recognised as a postgraduate specialty in a minority of jurisdictions. Travel medicine is to some extent necessitated by inequalities and inconsistencies in global health, and travel medicine practitioners are obliged to be familiar with the sociocultural aspects of global health and the burden of disease in host countries. Deterioration and improvements in global health can have a direct influence on the health outcomes of international travellers.

Scientometrics is a field of study related to data science, which concerns itself with the measurement and analysis of published scholarly literature. ${ }^{1}$ Scientometric and citation analyses have been published in relation to the most cited articles in travel medicine and articles published by leading journals in the field. ${ }^{2-5}$ The International Journal of Travel Medicine and Global Health (IJTMGH) is the only peerreviewed specialised travel medicine journal currently published in the Middle East, Africa or Asia. Published quarterly as an online, open access journal by the International Travel Medicine Center of Iran, it has been in existence since 2013. It uniquely addresses both travel medicine and global health issues and its editorial board comprises members drawn from 15 countries around the world. We aimed to conduct the first scientometric evaluation of articles published in IJTMGH, in order to gain insights into the development of travel medicine as a scholarship domain and to characterise the linkages between global health and travel medicine.

Copyright $\odot 2021$ The Author(s). This is an open-access article distributed under the terms of the Creative Commons Attribution License (http:// creativecommons.org/licenses/by/4.0), which permits unrestricted use, distribution, and reproduction in any medium, provided the original work is properly cited. 


\section{Methods}

All articles published in IJTMGH were accessed via the journal website at http://www.ijtmgh.com over a twomonth period in January-February 2021. Articles were deemed eligible for inclusion if they had been published in IJTMGH from its inception to the most recently published volume 9, issue 1 (winter 2021). Data relating to individual articles were extracted from the PDF file of the article and its accompanying metadata, and entered into a Microsoft Excel 2016 database. The principal discipline area of each article was categorised as either travel medicine or global health. The subject theme(s) which most closely reflected the content of each article was also recorded. Additionally, the content of travel medicine articles was mapped to one or more of the seven subject domains of the Body of Knowledge syllabus of the International Society of Travel Medicine (2017 version). ${ }^{6}$ The article category was indicated for each article from a list of 14 available options in the instructions for authors section of the journal website.

Details of the geographical origin of articles were documented, to include country or countries associated with the authors' institution(s) and the institutional affiliation of authors. The number of authors and institutions per article was determined in each case as an index of academic collaboration. The total article output from individual authors who published in IJTMGH was obtained from the journal website. The presence of funding for each study was established by consulting the obligatory funding statement at the end of each article. The level of attention given to each article was derived from the number of views and downloads received by each published article. Citation counts for each article were obtained by cross-referencing with Google Scholar. Data were independently verified for accuracy by two researchers (WWO and GTF). The Strengthening the Reporting of Observational Studies in Epidemiology (STROBE) guidelines for reporting observational cohort studies were applied where applicable to our study. ${ }^{7}$

\section{Results}

The IJTMGH is currently publishing articles in its ninth volume. At the time of writing, 240 articles have been published in the journal, the majority of which were original research articles $(53.8 \%, \mathrm{n}=129)$, followed in frequency by review articles $(15.4 \%, \mathrm{n}=37)$, and letters to the editor $(11.3 \%$, $\mathrm{n}=27)$. There were no missing data in our database. Less than a quarter $(22.5 \%, \mathrm{n}=54)$ of published articles reported a funding source. The mean number of authors per published article was 3.8. Articles with three authors were the most frequently published $(21.7 \%, \mathrm{n}=52)$. The total number of institutions involved in this set of publications was 189 , with the leading institutions listed in Table 1. Baqiyatallah University of Medical Sciences in Iran was the source of the largest number of articles in this journal $(25.4 \%, n=61)$. The mean number of institutional affiliations per journal article was 1.9. The majority of articles had a single institutional affiliation $(44.4 \%, \mathrm{n}=106)$ or arose from two institutions $(31 \%, n=74)$. There were 39 countries of origin of the articles published in IJTMGH, with the leading sources of articles being Iran (48.8\%, $\mathrm{n}=117)$, United States of America (13.8\%, $\mathrm{n}=33)$, and Republic of Ireland $(8.8 \%, \mathrm{n}=21)$.

The majority of IJTMGH articles have been cited $(65 \%$, $\mathrm{n}=165$ ) at least once. The mean number of cumulative citations per journal article was 3.5, with the most cited article by Nehrir et al, a systematic review of competency in nursing students, having received 37 citations at the time of writing. Of the 10 most cited articles (Table 2), five related to medical or health tourism. The majority of articles belonged to the general category of travel medicine $(62 \%, n=149)$, with $38 \%$ of articles $(n=91)$ being focused on global health and non-travel related infectious diseases. The 149 travel medicine-related articles mapped onto the ISTM Body of Knowledge syllabus (Figure 1), with the majority of articles addressing the domain of pre-travel assessment of travellers $(49.7 \%, \mathrm{n}=74)$, including the sub-domains of patient evaluation, special populations of travellers, special itineraries, prevention and self-treatment, and communication of risks to travellers.

The most common thematic designations of IJTMGH articles were medical and health tourism $(12.1 \%, \mathrm{n}=29)$ and travel health $(12.1 \%, \mathrm{n}=29)$, followed by COVID-19 (6.7\%, $\mathrm{n}=16)$. The mean number of article views and downloads from the journal website were 898 and 889 , respectively. The most viewed and downloaded articles are listed in Table 3.

Table 1. Leading Institutional Sources of IJTMGH Articles

\begin{tabular}{lcc}
\hline Institutional Affiliation & Country of Institution \\
\hline Baqiyatallah University of Medical Sciences & I.R. Iran & Number of Articles \\
National University of Ireland Galway & Republic of Ireland \\
Tehran University of Medical Sciences & I.R. Iran & 20 \\
International Medical University & Malaysia \\
Shahid Beheshti University of Medical Sciences & I.R. Iran \\
Isfahan University of Medical Sciences & I.R. Iran \\
Islamic Azad University & Multiple* \\
Iran University of Medical Sciences & I.R. Iran \\
Tarbiat Modares University & I.R. Iran \\
Shiraz University of Medical Sciences & I.R. Iran \\
\hline
\end{tabular}

* Campuses are located in Iran, UK, UAE, Lebanon, and Afghanistan. 
Table 2. Top 10 Most Cited Articles in IJTMGH

\begin{tabular}{|c|c|}
\hline Article Title & Citations (n) \\
\hline Competency in Nursing Students: A Systematic Review & 37 \\
\hline $\begin{array}{l}\text { Protective Effects of Educational Attainment Against Cigarette Smoking; Diminished Returns of American Indians and Alaska Natives in the National } \\
\text { Health Interview Survey }\end{array}$ & 34 \\
\hline Medical Tourism Attraction of Tehran Hospitals & 33 \\
\hline Race and Ethnic Differences in the Associations between Cardiovascular Diseases, Anxiety, and Depression in the United States & 27 \\
\hline The Factors in Development of Health Tourism in Iran & 25 \\
\hline Qualitative Examination of Health Tourism and Its Challenges & 21 \\
\hline Second-Hand Smoke Exposure at Home in the United States; Minorities' Diminished Returns & 20 \\
\hline A Study of the Effect of Advertising on Attracting Medical Tourism & 17 \\
\hline Income and Mental Well-Being of Middle-Aged and Older Americans: Immigrants' Diminished Returns & 17 \\
\hline
\end{tabular}

Table 3. Most Popular Articles Published in IJTMGH

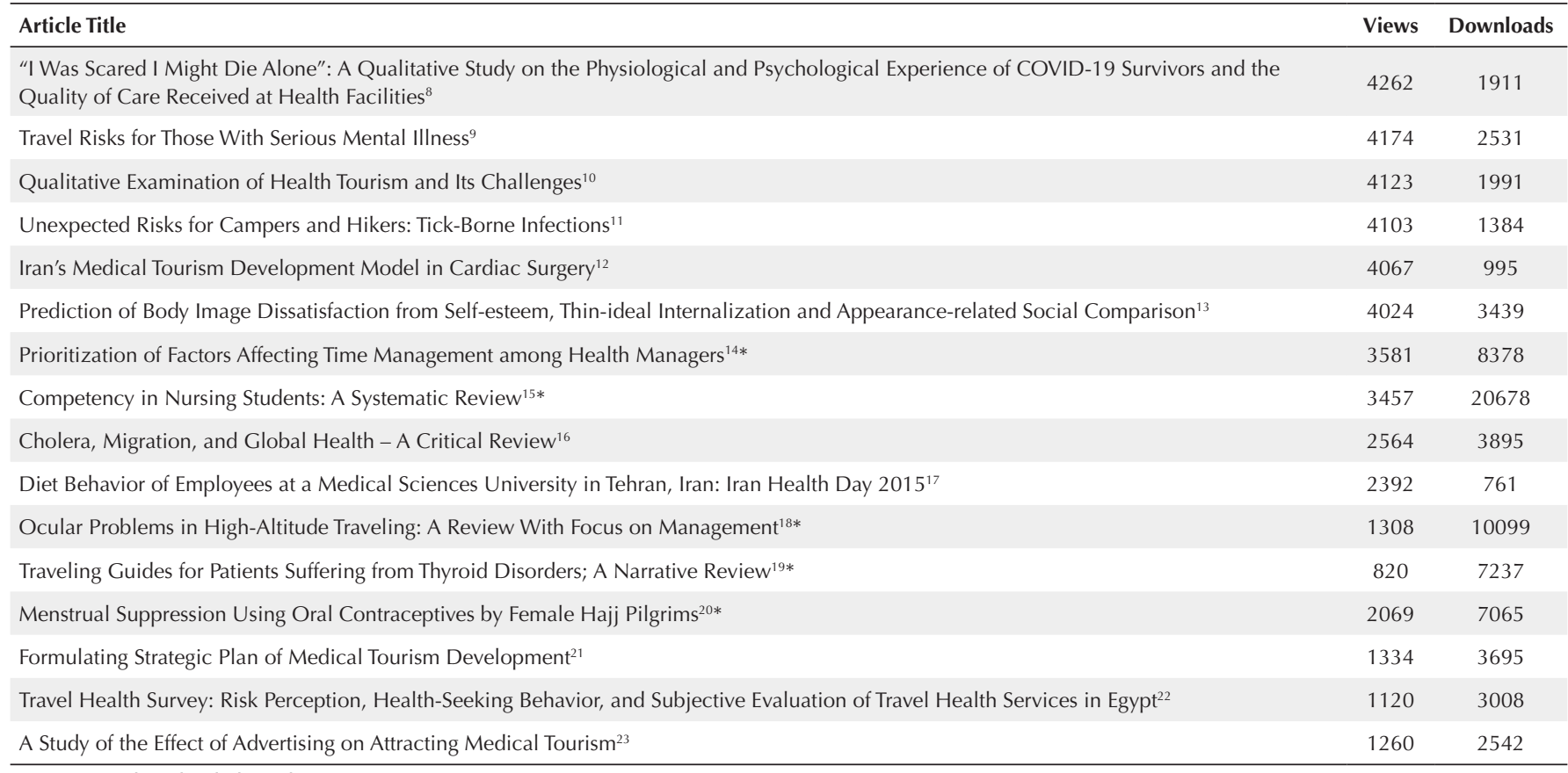

*Top 5 most downloaded articles

The most viewed article (4262 views) was a qualitative study of the experiences of COVID-19 survivors, while the most downloaded article (20678 downloads) was a systematic review of competency in nursing students. The authors who have published the largest number of articles to date in IJTMGH were Gerard Flaherty from Ireland $(n=21)$, Morteza Izadi from Iran $(n=17)$, Shervin Assari from the United States $(\mathrm{n}=17)$, Viroj Wiwanitkit from India/Thailand $(\mathrm{n}=10)$, and Ali Ayoubian from Iran $(n=10)$.

\section{Discussion}

The IJTMGH is now firmly established as one of the leading journals in its field. To date, there have been only four academic journals of travel medicine, but travel medicine research is often published in non-specialist journals, especially in the spheres of general internal medicine, infectious diseases, and public health. The diversity of its editorial board reflects the inclusivity of IJTMGH and its commitment to representing the full range of knowledge encompassed by travel medicine. Our scientometric analysis points to a broad coverage of topics within travel medicine and global health and it is consistent with the stated aims and scope of the journal. The emphasis on pre-travel assessment and consultation reflects trends observed in other leading travel medicine journals.,

Given the expertise of its host institution in medical and health tourism, it is not surprising that almost one in eight articles published in the journal related to these subject areas. Medical tourism is a burgeoning global industry involving the annual movement of an estimated 50 million travellers around the world, mostly from developed to developing countries with well established medical tourism services. ${ }^{24}$ The traditional dominance of dental, ophthalmologic and orthopaedic tourism is being challenged by the growing global demand for fertility, stem cell and bariatric surgery tourism..$^{25,26}$ Significant gaps remain in our understanding of the true scope of medical tourism, as well as the experiences of 


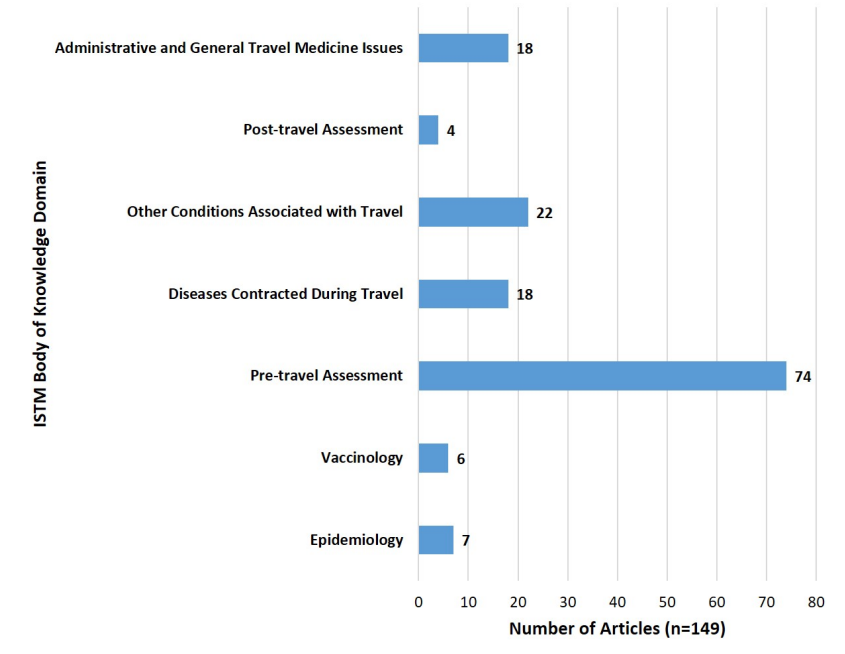

Figure 1. Curriculum Mapping of IJTMGH Travel Medicine Articles.

medical tourists and the clinical outcomes of the procedures that they undergo. IJTMGH provides an authoritative forum for the dissemination of original research and commentaries relating to medical tourism. It is also not surprising that so much attention has been given in IJTMGH to articles addressing various aspects of the COVID-19 pandemic, given its profound impact on international transit patterns.

The free open access nature of the journal greatly facilitates its accessibility and promotes early and unhindered citation of its articles. Although a detailed correlational analysis was beyond the scope of the current study, there was a high level of congruity between the lists of most cited and most accessed articles, reflecting the value of open access in dissolving barriers to the viewing and citing of journal output. The most cited and visited articles reflect the broad coverage of topics in this journal and the tendency for review articles in particular to attract larger numbers of citations from other authors. While the high visibility of the journal in the Middle East may account for the high proportion of accepted articles received from academics in Iran, our analysis revealed significant geographic diversity in the authorship and institutional affiliation of IJTMGH articles, with a growing trend for multiauthor and multi-institutional collaborations in evidence in more recent years.

Our study was limited by its lack of a comprehensive citation analysis, which would have included an examination of the source of citations, both self-citations and those received from other journals. This would provide further insights into the reach and influence of the journal and we recommend it be performed in the future as the journal's output continues to expand. A detailed mapping exercise at the level of individual topics would have yielded additional perspectives on the content of the journal. Many leading academic journals have established formal relationships with professional societies, which serve to extend the influence of their journals and increase their recognition among prospective authors. We recommend that the editorial team of IJTMGH give consideration to developing such partnerships, not least because to do so may assist in the development of travel medicine as a scholarly discipline throughout Western Asia. Citation metrics are dynamic and the data presented in our study are accurate only at the time of writing. Future periodic citation and bibliometric analyses will further illuminate the characteristics and performance of this reputable academic publication.

\section{Conclusion}

Our scientometric evaluation of all articles published in International Journal of Travel Medicine and Global Health provides useful insights into the content and geographic diversity of this journal and adds to our understanding of the development of travel medicine as a fertile academic entity with a rapidly growing evidence base.

\section{Authors' Contributions}

All authors contributed equally to the conception, design, execution, drafting and review of this manuscript. The final draft was read and approved by all authors.

\section{Conflict of Interest Disclosures}

Prof. Gerard Thomas Flaherty serves as a member of the editorial board of International Journal of Travel Medicine and Global Health.

\section{Ethical Approval}

Not applicable.

\section{Funding/Support}

This study has no financial support.

\section{References}

1. Liew CH, Flaherty GT. View from above: bibliometric and citation analysis of global high altitude medicine research. Int J Travel Med Glob Health. 2020;8(3):107-115. doi:10.34172/ ijtmgh.2020.19.

2. Flaherty GT, Browne DP. Citation analysis of the most influential publications in travel medicine. Int J Travel Med Glob Health. 2016;4(4):122-131. doi:10.21859/ijtmgh-040407.

3. Flaherty GT, Lim Yap K. Bibliometric analysis and curriculum mapping of travel medicine research. J Travel Med. 2017;24(5). doi:10.1093/jtm/tax024.

4. Oh KE, Flaherty GT. Travel medicine research in the new millennium: a bibliometric analysis of articles published in Travel Medicine and Infectious Disease, 2003-2019. Travel Med Infect Dis. 2020;33:101549. doi:10.1016/j.tmaid.2019.101549.

5. Khokhlov AN. How scientometrics became the most important science for researchers of all specialties. Moscow Univ Biol Sci Bull. 2020;75(4):159-163. doi:10.3103/s0096392520040057.

6. International Society of Travel Medicine. 2017. The ISTM Body of Knowledge for the Practice of Travel Medicine, Revised 2017. Available at: https://www.istm.org/bodyofknowledge2. Accessed March 23, 2021.

7. von Elm E, Altman DG, Egger M, Pocock SJ, Gøtzsche PC, Vandenbroucke JP. The Strengthening the Reporting of Observational Studies in Epidemiology (STROBE) statement: guidelines for reporting observational studies. Lancet. 2007;370(9596):1453-1457. doi:10.1016/s01406736(07)61602-x.

8. Nehrir B, Vanaki Z, Mokhtari Nouri J, Khademolhosseini SM, Ebadi A. Competency in nursing students: a systematic review. Int J Travel Med Glob Health. 2016;4(1):3-11. doi:10.20286/ 
ijtmgh-04013.

9. Izadi M, Pourazizi M, Alemzadeh-Ansari MH. Ocular problems in high-altitude traveling: a review with focus on management. Int J Travel Med Glob Health. 2017;5(2):41-45. doi:10.15171/ ijtmgh.2017.09.

10. Bahadori M, Salesi M, Ravangard R, et al. Prioritization of factors affecting time management among health managers. Int J Travel Med Glob Health. 2015;3(4):159-164. doi:10.20286/ ijtmgh-0304142.

11. Ghafari F, Izadi M, Pazham H. Traveling guides for patients suffering from thyroid disorders; a narrative review. Int $\mathrm{J}$ Travel Med Glob Health. 2015;3(4):149-152. doi:10.20286/ ijtmgh-0304146.

12. Dandehbor W, Kazemi M, Salehi Shahrbabaki $\mathrm{MH}$, et al. Menstrual suppression using oral contraceptives by female hajj pilgrims. Int J Travel Med Glob Health. 2016;4(4):111-114. doi:10.21859/ijtmgh-040405.

13. Awofeso N, Aldbak K. Cholera, migration, and global health - a critical review. Int J Travel Med Glob Health. 2018;6(3):92-99. doi:10.15171/ijtmgh.2018.19.

14. Ghanbari S, Hajinejad A, Rahmani P. Formulating strategic plan of medical tourism development. Int J Travel Med Glob Health. 2014;2(4):149-154.

15. Shahyad S, Pakdaman S, Shokri O. Prediction of body image dissatisfaction from self-esteem, thin-ideal Internalization and appearance-related social comparison. Int J Travel Med Glob Health. 2015;3(2):65-69. doi:10.20286/ijtmgh-030299.

16. El-Ghitany EM, Abdelmohsen M, Farghaly AG, Abd ElGawwad E, Abd El-Wahab EW. Travel health survey: risk perception, health-seeking behavior, and subjective evaluation of travel health services in Egypt. Int J Travel Med Glob Health. 2018;6(1):16-24. doi:10.15171/ijtmgh.2018.04.

17. Azimi R, Mahmoudi G, Esmaeili H. A study of the effect of advertising on attracting medical tourism. Int J Travel Med Glob Health. 2017;5(3):89-93. doi:10.15171/ijtmgh.2017.19.
18. Seeman MV. Travel risks for those with serious mental illness. Int J Travel Med Glob Health. 2016;4(3):76-81. doi:10.21859/ ijtmgh-040302.

19. Amouzagar S, Mojaradi Z, Izanloo A, Beikzadeh S, Milani M. Qualitative examination of health tourism and its challenges. Int J Travel Med Glob Health. 2016;4(3):88-91. doi:10.21859/ ijtmgh-040304.

20. Olufadewa II, Adesina MA, Oladokun B, et al. "I Was Scared I Might Die Alone": A Qualitative Study on the Physiological and Psychological Experience of COVID-19 Survivors and the Quality of Care Received at Health Facilities. Int J Travel Med Glob Health. 2020;8(2):51-57. doi:10.34172/ijtmgh.2020.09.

21. Dinc G, Demiraslan H, Doganay M. Unexpected risks for campers and hikers: tick-borne infections. Int J Travel Med Glob Health. 2017;5(1):5-13. doi:10.15171/ijtmgh.2017.02.

22. Noori F, Kargari M. Iran's medical tourism development model in cardiac surgery. Int J Travel Med Glob Health. 2016;4(2):5764. doi:10.20286/ijtmgh-04025.

23. Saberi Isfeedvajani M, Karimi Zarchi AA, Mehrabi Tavana A. Diet behavior of employees at a medical sciences university in Tehran, Iran: Iran Health Day 2015. Int J Travel Med Glob Health. 2016;4(3):92-95. doi:10.21859/ijtmgh-040305.

24. Kelley E. 2013. Medical tourism. World Health Organization. Available at: https://www.who.int/global_health_histories/ seminars/kelley_presentation_medical_tourism.pdf. Accessed March 23, 2021.

25. Connolly R, O'Brien T, Flaherty G. Stem cell tourism--a webbased analysis of clinical services available to international travellers. Travel Med Infect Dis. 2014;12(6 Pt B):695-701. doi:10.1016/j.tmaid.2014.09.008.

26. Choi PJ, Pereira RT, Killeen Á, Flaherty GT. Cross-sectional analysis of attitudes towards bariatric surgery tourism of patients attending a weight management program: a qualitative study. Int J Travel Med Glob Health. 2018;6(3):100-109. doi:10.15171/ijtmgh.2018.20. 